\title{
TRANSPORT AND MAGNETIC STUDIES OF SEGMENTED
}

\section{POLYACETYLENE}

\author{
F. ZUO
}

Department of Phyics, The Ohio State University, Columbus, OH 43210 (U.S.A.)

\section{A.J. EPSTEIN}

Department of Phyics and Department of Chemistry, The Ohio State University, Columbus, OH 43210 (U.S.A.)

X.-Q. YANG and D.B. TANNER

Department of Physics, University of Florida, Gainesville, FL 32611 (U.S.A.)

G. ARBUCKLE and A.G. MacDIARMID

Department of Chemistry, University of Pennsylvania, Philadelphia, PA 19104 (U.S.A.)

\begin{abstract}
Earlier studies of conducting polymers focused on polyacetylene, $(\mathrm{CH})_{\mathrm{x}}$, where extended conjugation lengths and crystallinity are present. We present here the results of a detailed study of temperature dependent magnetic susceptibility and ac and $\mathrm{dc}$ transport of $\left[\mathrm{CHD}_{\mathrm{y}}\right]$ and $\left[\mathrm{CHD}_{\mathrm{y}}{ }^{+z} \mathrm{~A}_{\mathrm{z}}\right]_{\mathrm{x}}$ where $\mathrm{A}$ is oxygen and iodine and $0.02 \leq \mathrm{y} \leq 0.17$. The $\mathrm{CHD}_{\mathrm{y}}$ introduce $\mathrm{sp}^{3}$ defects along the otherwise $\mathrm{sp}^{2}$ bonded polyacetylene chains and result in "segmentation" of the chain. Our results show that the presence of the $\mathrm{sp}^{3}$ bonded carbons has only a moderate effect on the conjugation of the pi band of polyacetylene.
\end{abstract}

\section{EXPERIMENTAL TECHNIQUE}

Cis-polyacetylene was prepared by the Shirakawa technique [1] at $-78^{\circ} \mathrm{C}$ and isomerized to the trans isomer by heating at ca. $150^{\circ} \mathrm{C}$ for approximately one hour. The trans $(\mathrm{CH})_{\mathrm{x}}$ was $\mathrm{n}$ doped to form $\left(\mathrm{CH}^{\cdot \mathrm{y}} \mathrm{Na}_{\mathrm{y}}{ }^{+}\right)_{\mathrm{x}}$ using sodium naphthalide solutions of 
<smiles>C/C=C\C=C/C=C\C(C)C</smiles><smiles>[2H]C([18OH])/C=C\C=C/C=C\C</smiles>

Fig. 1. Schematic diagram of introduction of $\mathrm{sp}^{3}$ defects on $(\mathrm{CH})_{\mathbf{x}}$ chain.

varying concentrations, according to the desired level of doping. Care was taken to assure homogeneous doping. The sodium doped film was then treated repeatedly with a deuterated alcohol, ROD, resulting in the formation of $\left(\mathrm{CHD}_{y}\right)_{\mathrm{x}}$, Figure 1, and the washing out of RONa. The iodine doped films were prepared by gas phase doping [2]. The level of iodine doping was determined by weight uptake. The maximum doping level achieved for $\left(\mathrm{CHD}_{0.17}\right)_{\mathrm{x}}$ was $\left(\mathrm{CHD}_{0.17}\left(\mathrm{I}_{3}\right)_{0.133}\right)_{x}$.

The magnetic susceptibility was measured via a Faraday technique [2]. The temperature dependent dc conductivity was measured using a four-probe technique [3]. The ac conductivity was measured using a General Radio Capacitance conductance bridge in a three terminal configuration [4]. Care was taken to assure that contact resistance did not lead to spurious behavior.

\section{EXPERIMENTAL RESULTS}

The magnetic susceptibility of representative samples of $(\mathrm{CH})_{x}$ and $\left(\mathrm{CHD}_{0.17}\right)_{x}$ is plotted versus temperature in Figure 2. The susceptibility can be expressed as a sum of a core diamagnetism, Pauli paramagnetism (if metallic with a finite density of states at $\mathrm{E}_{\mathrm{F}}$ ) and localized (Curie) spin contributions

$\mathrm{x}^{\mathrm{Exp}}=\mathrm{x}^{\text {Core }}+\mathrm{x}^{\text {Curie }}+\mathrm{x}^{\text {Pauli }}$

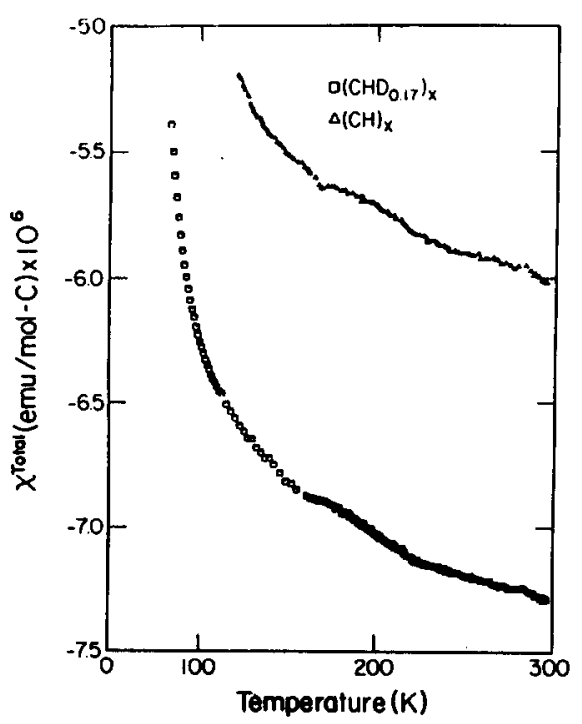

Fig. 2. Magnetic susceptibility vs. temperature for $(\mathrm{CH})_{\mathrm{x}}$ and $\left(\mathrm{CHD}_{0.17}\right)_{\mathrm{x}}$. 
Fitting the data to this expression reveals that the deuteration process results in an decrease of $x^{\text {Core }}$ from $-6.6 \times 10^{-6} \mathrm{emu} / \mathrm{mole}-\mathrm{C}$ to $-7.8 \times 10^{-6} \mathrm{emu} / \mathrm{mole}-\mathrm{C}$. The number of Curie spins remains nearly the same $\left(\mathrm{NCurie}\left((\mathrm{CH})_{\mathrm{x}}\right)=445 \mathrm{ppm}\right.$ and $\mathrm{NCurie}\left((\mathrm{CH})_{\mathrm{x}}\right)=$ $400 \mathrm{ppm})$ ) despite the samples being heavily $\mathrm{n}$-doped before treating with the alcohol. The $300 \mathrm{~K}$ electron spin resonance linewidth is $\sim 2$ gauss and increases as the temperature is decreased. The temperature dependent susceptibility of the heavily doped heavily deuterated sample, $\left(\mathrm{CHD}_{0.17}\left(\mathrm{I}_{3}\right)_{0.029}\right)_{\mathrm{x}}$ is shown in Figure 3 . The $\mathrm{x}^{\mathrm{Core}}$ predicted by the sum of the experimental $x^{\text {Core }}\left(\mathrm{CHD}_{0.17}\right)_{\mathrm{x}}$ and that for iodine $\left(-43.55 \times 10^{-6} \mathrm{emu} / \mathrm{mole}-\mathrm{I}\right)$ is $-11.7 \times 10^{-6} \mathrm{emu} / \mathrm{mole}-\mathrm{C}$. Fitting these data to Equation 1 shows the presence of a reduced number of Curie spins, $\sim 125 \mathrm{ppm}$, and $\mathrm{X}^{\mathrm{Pauli}}+\mathrm{X}_{\mathrm{Core}}=$ $-12.2 \pm 0.5 \times 10^{-6} \mathrm{emu} / \mathrm{mole} \mathrm{C}$. Hence, within experimental error, there is no significant $\mathrm{X}^{\mathrm{Pauli}}$ developed upon doping.

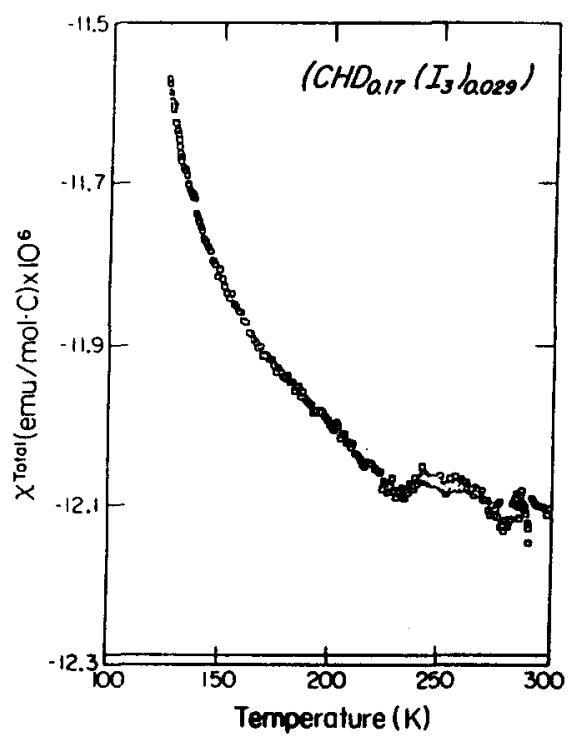

Fig. 3. Magnetic susceptibility vs. temperature for $\left[\mathrm{CHD}_{0.17}\left(\mathrm{I}_{3}\right)_{0.029}\right]_{\mathbf{x}}$.

The temperature and frequency dependence of the conductivity for $\left(\mathrm{CHD}_{0.17}\right)_{\mathbf{x}}$ and $\left(\mathrm{CHD}_{0.17}\right)_{x}$ doped to $0.0005(\mathrm{I})_{3}$ are shown in Figures $4 \mathrm{a}$ and $4 \mathrm{~b}$. The $\mathrm{o}(\mathrm{f}, \mathrm{T})$ of $\left[\mathrm{CHD}_{0.17}\right]_{x}$ resembles closely that for ammonia compensated polyacetylene [5]. However, after doping, it resembles closely that of lightly doped $(\mathrm{CH})_{\mathbf{x}}$ itself $[4,6]$. The temperature dependence of the dc conductivity for heavily $\mathrm{I}_{3}$ doped $\left[\mathrm{CHD}_{0.17}\left(\mathrm{I}_{3}\right)_{0.03}\right] \mathrm{x}$ is given in Figure 5. The conductivity at room temperature is $\sim 2.2 \times 10^{-2} \mathrm{ohm}^{-1} \mathrm{~cm}^{-1}$ and

$\sigma(\mathrm{T})=\mathrm{A}_{0} \mathrm{~T}^{-\frac{1}{2}} \exp \left[-\left(\mathrm{T}_{0}, \mathrm{~T}\right)^{t}\right]$

yields $\mathrm{T}_{0}=4.4 \times 10^{7} \mathrm{~K}$, a factor of ten larger than $(\mathrm{CH})_{\mathrm{x}}$ doped to the same level [3]. 


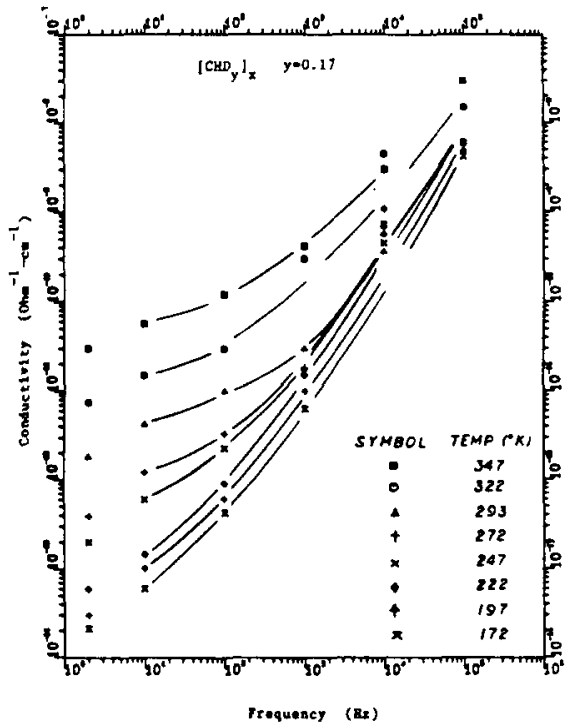

(a) $\left(\mathrm{CHD}_{0.17}\right)_{\mathrm{x}}$.

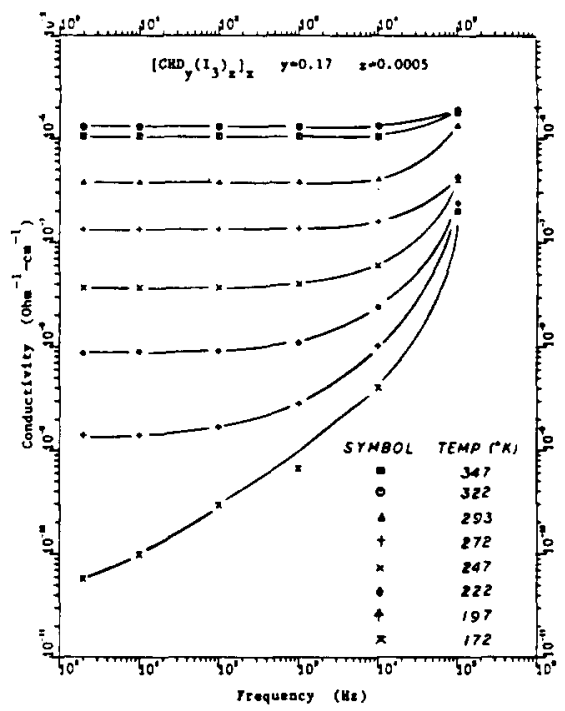

(b) $\left(\mathrm{CHD}_{0.17}\left(\mathrm{I}_{3}\right)_{0.0005}\right)_{\mathrm{x}}$.

Fig. 4. Log $\sigma$ vs. $\log f$ at constant temperatures. Note break in abscissa for $\mathrm{dc}$.

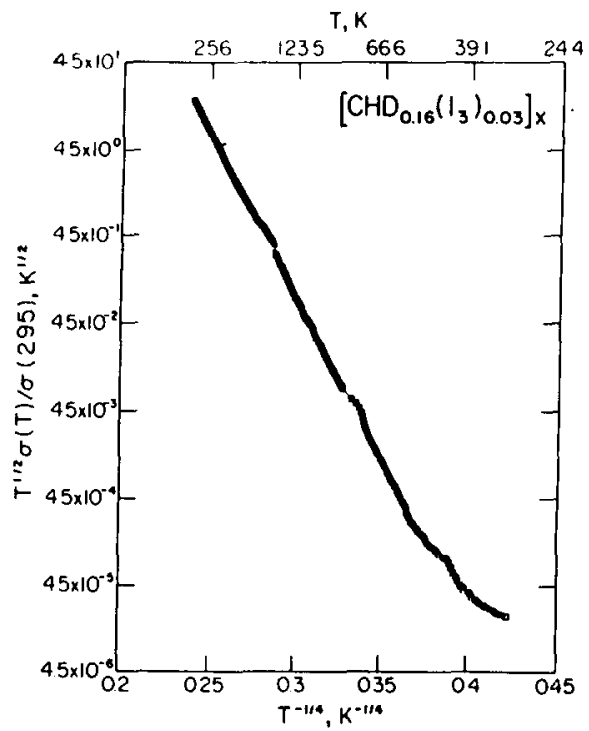

Fig. 5. $\log \left(\mathrm{T}^{t} \sigma / \sigma(295 \mathrm{~K})\right)$ vs $\mathrm{T}^{-t}$ for $\left[\mathrm{CHD}_{0.17}\left(\mathrm{I}_{3}\right)_{0.03}\right]_{x}$.

\section{DISCUSSION}

Incorporation of $\mathrm{CHD}$ units into the $(\mathrm{CH})_{\mathrm{x}}$ chains has a marked effect on the detailed nature of the conjugation of the pi electron bands. The increase in the experimental $X^{\text {Core }}$ with increase in $\mathrm{sp}^{3}$ content is in agreement with the estimated 
decrease in the Van Vleck paramagnetism contribution due to removal of double bonds from the chains. The essentially constant value of the number of Curie spins suggest that the number of neutral solitons remains unchanged as a result of the chemical treatment. The broadening of their ESR line width to $\sim 2$ gauss at room temperature implies a reduction in but not a complete blockage to the motion of the spins.

The semblance of the $\sigma(f, T)$ of $\left(\mathrm{CHD}_{0.17}\right)_{x}$ to that of ammonia compensated $(\mathrm{CH})_{x}[5]$ supports that the chemical process used to obtain the $\left(\mathrm{CHD}_{0.17}\right)_{\mathrm{x}}$ if effective at compensating nearly all the charge carrier in $(\mathrm{CH})_{\mathrm{x}}$. The temperature dependence of the dc conductivity of $\left[\mathrm{CHD}_{0.17}\left(\mathrm{I}_{3}\right)_{0.0005}\right]_{\mathrm{x}}$ could be fit to $\exp \left(-\left(\mathrm{T}_{0} / \mathrm{T}\right)^{\frac{1}{4}}\right)$ with $\mathrm{T}_{0}=2.4 \times 10^{9} \mathrm{~K}$, nearly identical to that of $(\mathrm{CH})_{\mathrm{x}}[4]$ while its frequency dependence is all similar to $(\mathrm{CH})_{\mathrm{x}}[4]$ suggesting that with the addition of a small number of charges to $\left(\mathrm{CHD}_{.17}\right)_{\mathbf{x}}$, its conduction process is quite similar to that for $(\mathrm{CH})_{\mathrm{x}}$.

At higher doping level, ie., $\left(\mathrm{I}_{3}\right)_{0.03}$, the susceptibility shows that the charges go into spinless states [7]. The spectroscopic data support that these states are solitons with a larger effective mass than in $(\mathrm{CH})_{\mathrm{x}}$. the layer $\mathrm{T}_{0}$ for $\sigma(\mathrm{T})$ reflect hopping of charges in more localized states.

To account for these experimental data, it becomes necessary to reexamine the effectiveness of $\mathrm{sp}^{3}$ bonded $\mathrm{CHD}$ units in interrupting the conjugation. The data presented here support that the $(\mathrm{CH})_{x}$ chain is remarkably robust and that the phenomenology developed for infinite polymers, including the relevance of solitons not polarons as the lowest energy state is appropriate despite the presence of sp $^{3}$-type defects.

\section{ACKNOWLEDGEMENTS}

This research is supported in part by US-NSF-DMR-80-22870 and NSF-DMR8416511.

\section{REFERENCES}

1 T. Ito, H. Shirakawa and S. Ikeda, J. Polym. Sci. Polym. Chem. Ed.,12 (974) 11; and $\underline{13}$ (1975) 1943.

2 A.J. Epstein, H. Rommelmann, M.A. Druy, A.J. Heeger and A.G. MacDiarmid, Solid State Commun., 38 (1981) 683.

3 A.J. Epstein, H. Rommelmann, R. Bigelow, H.W. Gibson, D.M. Hoffman and D.B. Tanner, Phys. Rev. Lett., 50 (1983) 1866.

4 A.J. Epstein, H. Rommelmann, M. Abkowitz and H.W. Gibson, Phys. Rev. Lett., 23 (1981) 1549 . 
5 A. J. Epstein, in T. Skotheim (ed.), Handbook of Physics, Marcel Dekker, 1986, p. 1049.

6 A.J. Epstein, H. Rommelmann and H.W. Gibson, Synth. Met., 9 (1984) 103.

7 X.Q. Yang, D.B. Tanner, G. Arbuckle, A.G. MacDiarmid and A.J. Epstein, Synth. Met., 17 (1987) 277 (these Proceedings). 